\title{
Ketamine Administration During Waking Increases Delta EEG Intensity in Rat Sleep
}

Inwin Feinberg, M.D. and Ian G. Campbell, M.S.

\begin{abstract}
Ketomine is known to increase the metabolic rate of limbic hain structures. We exploited this action to test a hypothesis of the homeostatic model of delta sleep: that a increase in the waking metabolic rate of plastic muronal systems would increase delta electromaphalographic (EEG) intensity in subsequent mopid-eye-movement (NREM) sleep. In separate aperiments, we gave intraperitoneal injections of tomine to Sprague-Dawley rats of either 15, 25, or 50 $\mathrm{mo} / \mathrm{kg}(0.055,0.091,0.18 \mathrm{mmol} / \mathrm{kg})$ three times, at aproximately hourly intervals, during the dark (waking) rriod; the last dose was given 4 to 5 hours before onset dige light (sleep) period. After ketamine, both NREM duntion and delta EEG intensity (amplitude and
\end{abstract}

incidence) increased significantly over control (saline injections) levels. The magnitude of this increase places it among the largest pharmacologically induced stimulations of delta sleep yet observed. The interpretation of this effect is complicated by the fact that ketamine produces widespread metabolic changes throughout the brain and it also acts on several receptor classes. However, since ketamine's major action is noncompetitive blockade of the cation channel gated by the N-methyl-D-aspartate receptor, our data join recent observations that suggest that excitatory amino acid receptor systems are involved in sleep regulation. [Neuropsychopharmacology 9:4148, 1993] orwords: Sleep; EEG; Delta; Period/amplitude analysis; Nomine; NMDA receptors; Rat

This experiment was undertaken to test a prediction crived from the original homeostatic model of human low-wave sleep (Feinberg 1974). One component of this model holds that an increase in the waking metabicrateof plastic neuronal structures will increase the intensity of delta electroencephalogram (EEG) in subequent nonrapid-eye-movement (NREM) sleep. This momonent was based on indirect evidence. Children trehigher rates of cerebral metabolism (Kennedy and Sokoloff 1957; Chugani et al. 1987), presumably as a sult of more intense plastic neuronal activity. They to have, proportionally, a higher incidence and am-

from the Psychiatry Service, VA Medical Center, Martinez, and Department of Psychiatry, University of California, Davis, Cetmia.

Address correspondence to: Irwin Feinberg, M.D., Sleep Lab, TB iniversity of California, Davis, California 95616.

haived April 10, 1992; revised January 19, 1993; accepted January D. 1993. plitude of delta waves during NREM sleep. (Elsewhere, we have shown that the ontogenetic curves for human cortical metabolic rate and delta wave amplitude parallel that for synaptic density; all three brain variables show a steep decline over late childhood and adolescence [Feinberg et al. 1990b]. Although synaptic reorganization [toward fewer but more effective synapses] is a major part of brain reorganization during the second decade of life, we speculate that this is only one component of a process in which neurons lose relative equipotentiality and become "committed" to specific roles in neural networks. In this revised model, both delta amplitude and waking metabolic rate are proportional to the number of uncommitted neurons [Feinberg et al. 1990a]).

Deoxyglucose studies of the brain effects of ketamine and its structural analogs, 1-(1-phenylcyclohexyl) piperidine $(\mathrm{PCP})$ and $\mathrm{MK}-801$, suggested a more direct, albeit limited test of the intensity hypothesis. These drugs increase glucose utilization in plastic structures in the rat brain (hippocampus, cingulate and entorhinal cortex) and decrease uptake in sensory and other 
cortical areas (Meibach et al. 1979; Crosby et al. 1982; Hammer and Herkenham 1983; Weissman et al. 1987; Kurumaji et al. 1989). Recognizing that the interpretation of any sleep changes would be complicated by the multiple actions of ketamine on both brain metabolism and neurotransmitter systems, we nevertheless administered ketamine to rats as an experimental "first approach" to the hypothesis that the intensity of delta EEG in NREM sleep depends in part on the metabolic rate of plastic neuronal systems during waking.

\section{MATERIALS AND METHODS}

Electrodes were implanted under pentobarbital (65 $\mathrm{mg} / \mathrm{kg}, 0.26 \mathrm{mmol} / \mathrm{kg}$ ) and methoxyflurane anesthesia into Sprague-Dawley rats $(n=10)$ each weighing between 300 to $350 \mathrm{gm}$ for chronic EEG recording. Cortical EEG was recorded from stainless-steel screws implanted through the skull over the frontoparietal cortex. Hippocampal EEG was recorded from a stereotactically placed bipolar electrode, except for three animals where hippocampal theta was measured from midline cranial screws. Electromyograms (EMG) were recorded from stainless-steel wires embedded in the nuchal muscles.

Two or more weeks after surgery, the rats were habituated to the recording cable on one or more occasions lasting at least 12 hours. A commutator and counterbalance for the cable's weight allowed each rat to move freely about its cage. An experimental session consisted of 3 consecutive days: a 24-hour period for further adaptation during which the animals were attached to the cable in the recording cage with the equipment turned off; a 24-hour recording period in which they received three intraperitoneal (IP) injections of saline given at about the same time intervals as the corresponding ketamine dosage; and a 24 -hour recording period in which they received three IP ketamine $\mathrm{HCl}$ injections of either $15(n=5), 25(n=4)$ or $50 \mathrm{mg} / \mathrm{kg}$ $(n=5)[0.055,0.091$, or $0.18 \mathrm{mmol} / \mathrm{kg}$ ]. One rat was studied under both the 15 and $25 \mathrm{mg} / \mathrm{kg}$ doses, one rat was studied under both the 25 and $50 \mathrm{mg} / \mathrm{kg}$ doses, and one rat was studied under all three doses so that the 10 rats provided 14 saline-ketamine comparisons. The injections were given during the dark (wake) period under dim red illumination. A 12-hour light/dark cycle was maintained for at least 2 weeks prior to the study. For those animals who received more than one dose, at least 1 week separated the experiments.

The actual duration of ketamine's metabolic effects is not known. In an effort to produce a sustained increase in limbic metabolism, we gave three IP ketamine injections, waiting for the behavioral effects of each injection to disappear before giving the next. For each animal, the saline trials preceded the ketamine injections.
We used this order rather than counterbalancing because we did not know whether any ketamine effects on sleep would induce compensatory reactions during the subsequent saline condition. This schedule raises the possibility that the sleep EEG changes we observed after ketamine were actually due to ongoing habituation. However, the apparent dose dependence of our findings (see below), and the fact that we have not found such habituation effects on delta in other studies with 48 hours of baseline recording renders this possibility quite remote.

Cortical and hippocampal EEG and nuchal EMG were amplified and recorded with a polygraph (Grass Model 78; Quincy, MA). The 1/2 amplitude low-frequency filters were set at $0.3 \mathrm{~Hz}$ for the EEG signals and $3 \mathrm{~Hz}$ for the EMG. The amplified signals were digitized and analyzed online with PASS PLUS, a commercially available microcomputer program (Delta Software; St. Louis, MO) that uses the zero-cross and zero-first derivative algorithms that we have applied to the EEG of human sleep for over 18 years; their reliability and validity have been established (Feinberg et al. 1978, 1980).

Zero-cross integrated amplitude (IA) in cortical and hippocampal EEG and in nuchal EMG was summed for each 10-second epoch and plotted separately on the computer monitor; 36010 -second epochs ( 1 hour) were displayed on a standard monitor. These graphic dis. plays were scored visually into NREM sleep, REM sleep, and waking using the traditional criteria for vigilance states in the rat with one addition: REM was identified by a precipitous decline in hippocampal 0 to $3 \mathrm{~Hz}$ EEG, in addition to the increase in theta. Scoring a 12-hour record required about 2 hours with this method; for an illustration and further description of this method of computer-assisted visual sleep state scor. ing, see Campbell and Feinberg (1993).

The statistical analyses we employed addressed two questions. First, did ketamine (all doses together) alter subsequent sleep EEG, especially delta measures? This question was tested with a repeated-measures analy. sis of variance (ANOVA) using Program BMDP 2V (Dixon et al. 1990) with time (hour of light period) and condition (ketamine versus saline) as repeated mersures (within factors). This analysis also tested for linear and quadratic trends in NREM sleep across the light period.

Second, we addressed the question of dose dependence. Originally, we had hoped to conduct a pure within-S dose-response study, with each animal receiv. ing all three doses. We did not achieve this aim due to electrode failures. As a consequence, we were ur able to perform a within-S ANOVA or a pure between-s ANOVA. We nevertheless applied BMDP Program2V, using saline values as a covariate, time as a repeated 
measure, and dose as a between-S grouping. In this analysis, animals who receive more than one dose were rated as separate subjects. This limitation is discussed further below.

\section{RESULTS}

\section{Immediate Effects of Ketamine}

The behavioral responses to 25 and $50 \mathrm{mg} / \mathrm{kg}$ were virtually immediate. They consisted of head swinging and increased locomotion followed by ataxia. Dark-period steep following the higher doses was reduced (see below). The effects on waking EEG were as described by French and Domino (1988). For $15 \mathrm{mg} / \mathrm{kg}$, the behavioral and EEG responses were delayed in onset, weaker (sometimes unapparent), and shorter lived. The third and last ketamine dose was injected an average of 3 hours 55 minutes, 4 hours 34 minutes, and 4 hours 59 minutes (for the 15,25 , and $50 \mathrm{mg} / \mathrm{kg}$ doses) before the onset of the light (sleep) period. The behavioral effects persisted for durations roughly proportional to the dose, averaging 26,43 , and 88 minutes after the third injections. Thus, onset of the light (sleep) period ocarred, on average, 3 hours 33 minutes, 3 hours 49 minutes, and 3 hours 25 minutes after the behavioral flects induced by 15,25 , and $50 \mathrm{mg} / \mathrm{kg}$ were no longer evident.

\section{Efects of Ketamine on NREM REM Durations}

The sleep measures were analyzed by hour for the first II hours of the light (sleep) period. Data for the 12th lour were lost because of limited disk space at the time the study was initiated.

To illustrate graphically the effects of ketamine on rep, we combined the data for all 10 rats who received anine (COMB); if a rat received more than one dose, th the results for the highest dose were included. The COMB group includes three rats who received 15 $\mathrm{m} / \mathrm{kg}$, two who received $25 \mathrm{mg} / \mathrm{kg}$, and five who recived $50 \mathrm{mg} / \mathrm{kg}$. Statistical analyses are presented in Tole 1 for the main sleep variables.

Figure $1 A$ and $B$ show NREM and REM durations minutes) under ketamine and saline conditions for wors 1 to 11 of the light period for the COMB group. Ansysis of variance (Table 1) revealed that total NREM mep was increased significantly by ketamine. Figure 14 suggests that the ketamine effect on NREM sleep coured in the second half of the sleep period. For Dus 1 to 6 the difference between ketamine and sawas small (5.1\%) whereas for hours 7 to 11 it was (22.1\%) and significant (post-hoc paired I $3.02 ; p<.02$ ). Because almost all of the ketamine mulation of delta intensity occurred in the first 6 hours of sleep (see below), this result suggests that ketamine first increased NREM sleep intensity and then its duration.

There were no significant effects of ketamine on REM sleep duration at any dose. Although Figure 1B suggests that ketamine suppressed REM sleep in the first part of the sleep period for the COMB group, a posthoc $t$-test for hours 1 to 4 was not significant.

\section{Effects of Ketamine on Cortical Delta (1 to $4 \mathrm{~Hz}$ ) EEG within NREM}

Here we present results for NREM cortical delta ( 1 to $4 \mathrm{~Hz}$ ) EEG measured by the zero-cross component of PASS PLUS. We analyzed four waveform measures: IA, which for delta frequencies is almost exactly proportional to spectral power as measured with the Fast Fourier Transform (FFT) (Ktonas and Gosalia 1981; Feinberg 1989; Uchida et al. 1992); time, occupied by 1 to $4 \mathrm{~Hz}$ (almost entirely determined by wave incidence); average sample amplitude (ASA $=\mathrm{IA} /$ time in 1 to $4 \mathrm{~Hz}$ ); and mean frequency of waves within 1 to $4 \mathrm{~Hz}$.

Figure $2 \mathrm{~A}$ to $\mathrm{D}$ plots the results for cortical 1 to 4 $\mathrm{Hz}$ EEG in NREM sleep by hour of the light period for the COMB group. Compared to the saline controls, sleep following administration of ketamine showed significant increases in the amplitude and density of delta and a decrease in 1 to $4 \mathrm{~Hz}$ mean frequency.

Thus, administration of ketamine during waking increased the average amplitude of delta waves (ASA) and the rate of delta wave production (IA/minute and time/minute of NREM). As NREM duration itself increased after ketamine, there were strong and significant (Table 1) increases above saline levels in total IA $(39 \%)$ and total time occupied by delta EEG (32\%).

Table 1 also shows that, as predicted by the original homeostatic delta model (Feinberg 1974) and as found in subsequent studies of rat sleep by others (Bergmann et al. 1987; Trachsel et al. 1988), delta amplitude and density showed significant declining trends across sleep. Mean frequency within 1 to $4 \mathrm{~Hz}$ increased as amplitude declined. The inverse relation of EEG frequency and amplitude has long been known. In the NREM EEG of human sleep, amplitude has been shown to vary inversely as a power of frequency (Feinberg et al. 1984).

Each delta measure exhibited a highly significant linear trend across the light period. Tests for curvature (quadratic trend) were significant for some measures. A more detailed analysis of normative delta trends across NREM sleep of both the light and dark periods is presented in Campbell and Feinberg (1993). Ketamine altered the across-NREM trend of ASA, time in delta/minute and IA/minute (time $\times$ condition interaction; Table 1). 
Table 1. Repeated-Measures ANOVA ${ }^{1}$ for NREM and REM Durations and Delta (1 to $4 \mathrm{~Hz}$ ) EEG Measures within NREM: Effects of Condition (Saline vs.

Ketamine) and Trend Analysis Across Hours of the Light Period

\begin{tabular}{|c|c|c|c|c|c|}
\hline & \multirow[b]{2}{*}{$\begin{array}{c}\text { Condition } \\
F(1,9)\end{array}$} & \multicolumn{3}{|c|}{ Time $^{2}$} & \multirow{2}{*}{$\begin{array}{c}\text { Interaction } \\
\text { (Time } \times \text { Cond) } \\
F(10,90)\end{array}$} \\
\hline & & $F(10,90)$ & $\begin{array}{c}\text { (Linear) } \\
F(1,9)\end{array}$ & $\begin{array}{l}\text { (Quad) } \\
F(1,9)\end{array}$ & \\
\hline \multicolumn{6}{|l|}{ Sleep durations } \\
\hline NREM min & $14.4^{\star \star}$ & $2.7^{\star}$ & 4.3 & 2.1 & 1.4 \\
\hline REM min & 0.16 & $6.4^{\star \star \star}$ & $19.1^{\star *}$ & $21.8^{\star \star \star}$ & 1.1 \\
\hline \multicolumn{6}{|l|}{ Delta measures } \\
\hline Avg sample amp & $7.94^{*}$ & $18.2^{\star \star \star}$ & $19.8^{\star \star}$ & $50.3^{\star \star}$ & $4.8^{\star}$ \\
\hline Time in delta/min & $22.3^{* * *}$ & $76.2^{\star \star \star}$ & $150.8^{\star \star *}$ & 0.42 & $4.5^{\star \star}$ \\
\hline Total time in delta & $22.1^{\star * *}$ & $12.9^{\star \star \star}$ & $63.8^{\star \star \star}$ & 0.5 & 1.3 \\
\hline $\mathrm{IA} / \mathrm{min}$ & $9.7^{\star}$ & $21.2^{\star \star \star}$ & $25.3^{\star \star *}$ & $26.9 * \star \star$ & $3.9^{*}$ \\
\hline Total IA & $18.0^{\star *}$ & $9.2^{\star \star \star}$ & $16.6^{\star \star}$ & 0.16 & 1.3 \\
\hline Mean delta freq. & $35.9 * \star \star$ & $27.8^{\star \star \star}$ & $47.8^{\star \star \star}$ & $33.6^{\star \star \star}$ & 1.6 \\
\hline \multicolumn{6}{|l|}{${ }^{*} p<0.05$} \\
\hline
\end{tabular}

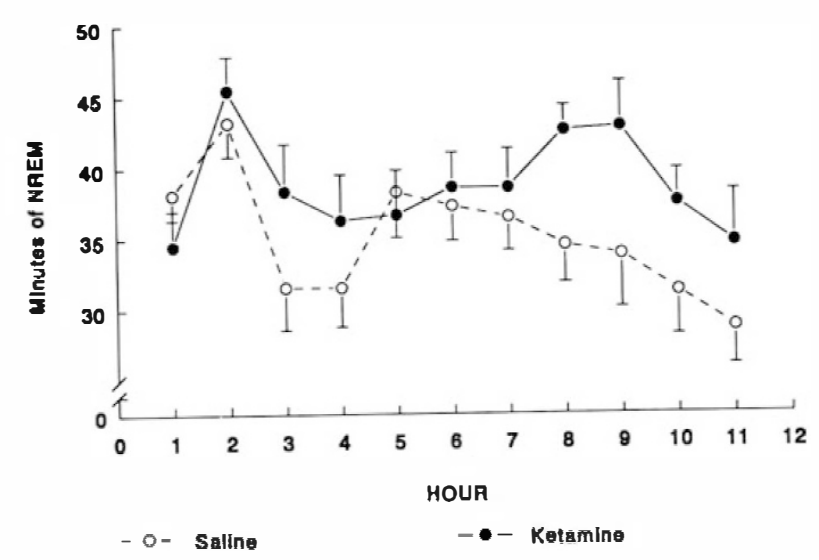

B

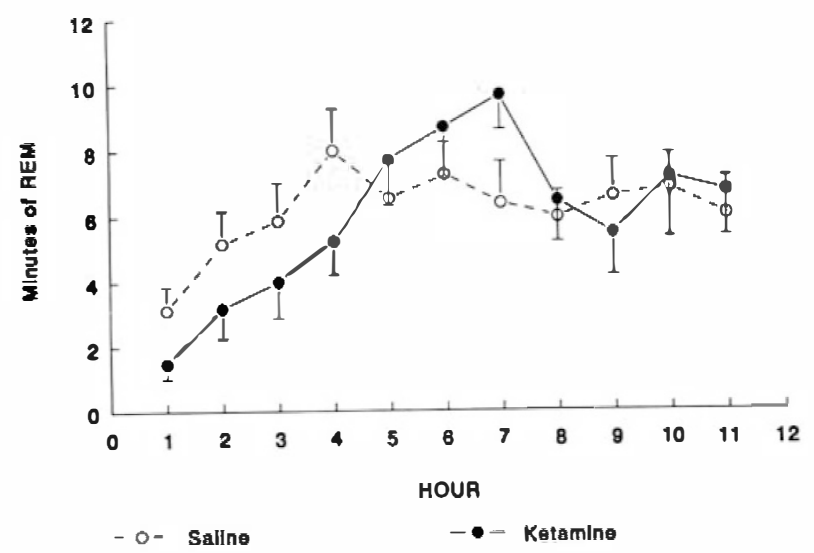

\section{Dose-Response Effects of Ketamine}

Figure 3 points to strong dose dependence of the main delta measures. However, because we did not have a sufficient number of animals receiving each dose to carry out a pure between S's ANOVA, the evidencefor dose dependence in Table 2 must be considered sug. gestive rather than conclusive.

Table 2 suggests that ketamine's dose-responsere lations were significant for the two main measures of delta intensity, ASA and time/minute of NREM sleep. Although IA/minute is the product of ASA and time/minute, its dose-response effects did not quite reach statistical significance $(p=.055)$. However dose-response relations for total IA were statistically significant as were those for total time occupied by delta Dose effects for mean frequency did not reach statisti cal significance.

\section{Comparison of Ketamine Effects $(50 \mathrm{mg} / \mathrm{kg})$ on Delta Sleep with Those Produced by 24 Hours of Total Sleep Deprivation}

The behavioral excitement caused by ketamine pm duced a significant loss of NREM sleep during the dat

Figure 1. Mean (and SEM) minutes of NREM (A) andREO (B) sleep in each hour of the light period for rats who recen: three injections of ketamine (COMB group, $\boldsymbol{n}=10$ ) orsalit during the dark (waking) period. Ketamine significantlg creased NREM sleep in the second half of the light peid (see text). The ANOVA revealed no significant effect of mine on REM sleep. The apparent suppression of REM sid in hours 1 to 4 was not significant with a post-hoc t-test 


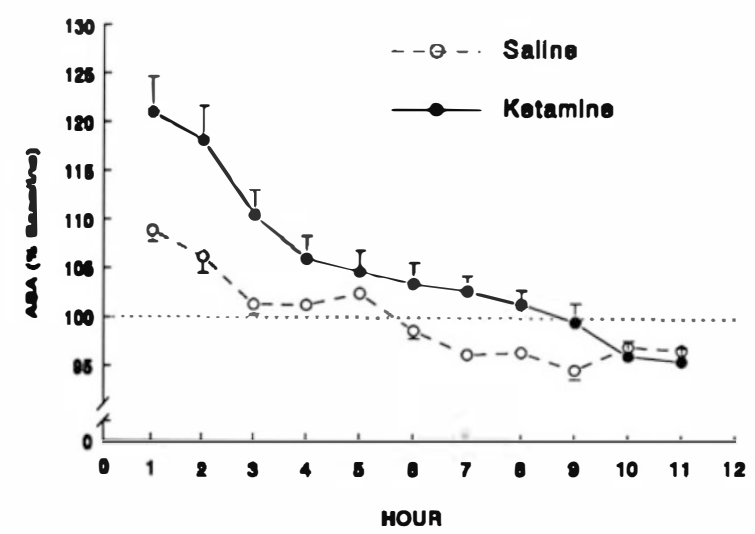

C

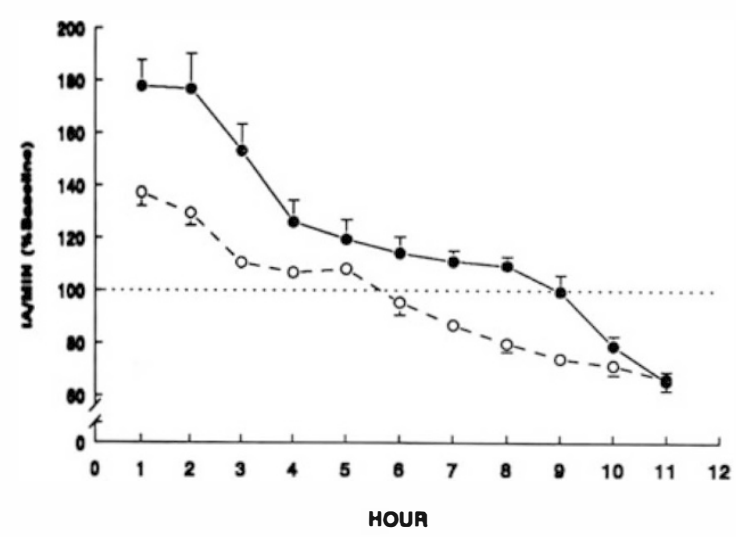

B

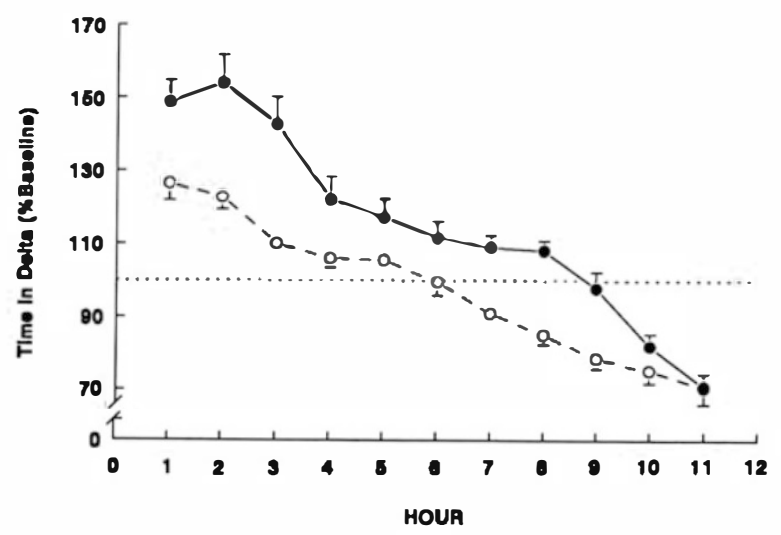

D

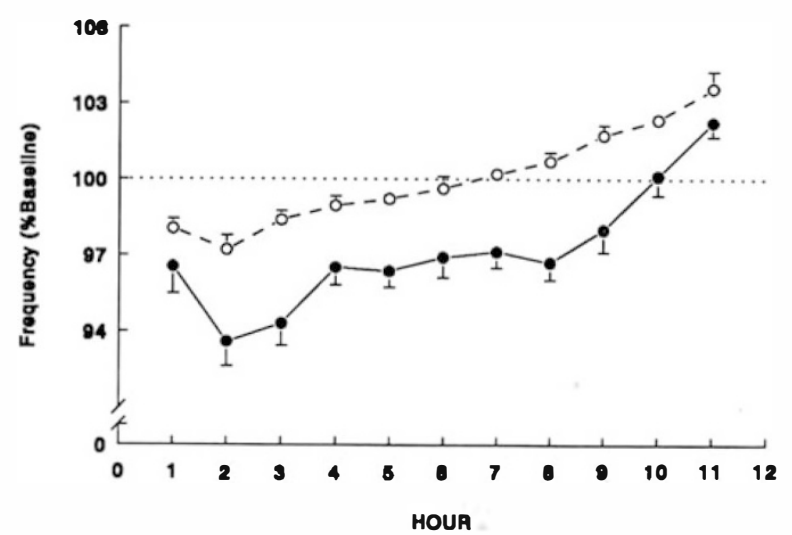

Fore 2. Effects of ketamine and saline on delta ( 1 to $4 \mathrm{~Hz}$ ) waveform characteristics in NREM sleep during hours 1 to Il of the light period (COMB group, $n=10$ ). Because of the typically wide interindividual variation in rat EEG, all values mexpressed as a percent of the 11-hour saline mean (shown by the dotted line at $100 \%$ ). Absolute values can be approxiarted by multiplying the graphed value by the saline mean and dividing by 100 . (A) Average sample amplitude, a measure d the average amplitude of delta waves (saline mean $=76.2 \mu \mathrm{V}$ ). (B) Seconds occupied by 1 to $4 \mathrm{~Hz}$ waves/minute of NREM Iep (saline mean $=14.5 \mathrm{sec}$ ). (C) Integrated amplitude (the period-analysis measure most closely related to power density wh spectral analysis) (saline mean $=1150 \mu \mathrm{V} \times \mathrm{sec}$ ). (D) Average frequency of waves within the 1 to $4 \mathrm{~Hz}$ frequency bund (saline mean $=2.89 \mathrm{~Hz}$ ).

period. After $50 \mathrm{mg} / \mathrm{kg}$ ketamine, the animals averaged if minutes of NREM during the dark period as compared with 235 minutes after saline, a net loss of 161 mutes or slightly less than 3 hours. This NREM sleep bss could have produced the delta increase during the wht period.

We evaluated this possibility by comparing the tomine stimulation of delta with that produced by dep deprivation. The maximum duration of sleep eprivation under $50 \mathrm{mg} / \mathrm{kg}$ of ketamine would have hen 8 hours, since the first injection was 8 hours prior - light-period onset. We compared the data on 50 kg ketamine with results in our laboratory for 24 bours of total sleep deprivation ( $n=5$ in each study). Tobler and Borbely (1986) found a correlation between amount of sleep deprivation and the increase in delta power during the recovery period. Thus, our 24-hour deprivation data should overestimate the effect of the maximum 8-hour sleep deprivation caused by ketamine. We used gentle handling rather than forced locomotion to accomplish the deprivation because handling is less stressful to the rat and results in more normal postdeprivation behavior (Franken et al. 1991). The same methods of scoring and analysis were applied in the deprivation and ketamine experiments.

Figure 4 compares the effects on delta amplitude of the $50-\mathrm{mg} / \mathrm{kg}$ ketamine condition with those produced by 24 hours of deprivation. The initial increase in delta IA/minute was similar in the two conditions, but the ketamine effect was far more sustained. As a 
$15 \mathrm{mg} / \mathrm{Kg}$
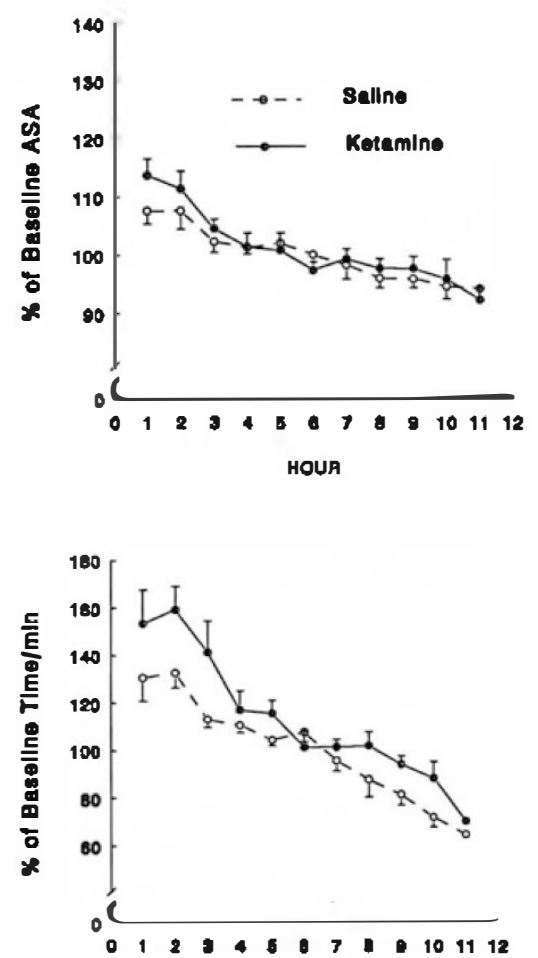

$25 \mathrm{mg} / \mathrm{Kg}$
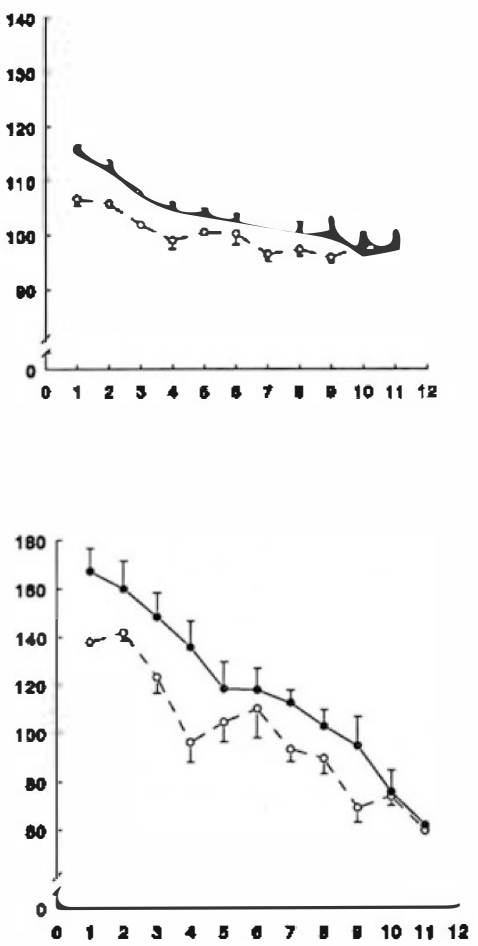

$50 \mathrm{mg} / \mathrm{Kg}$
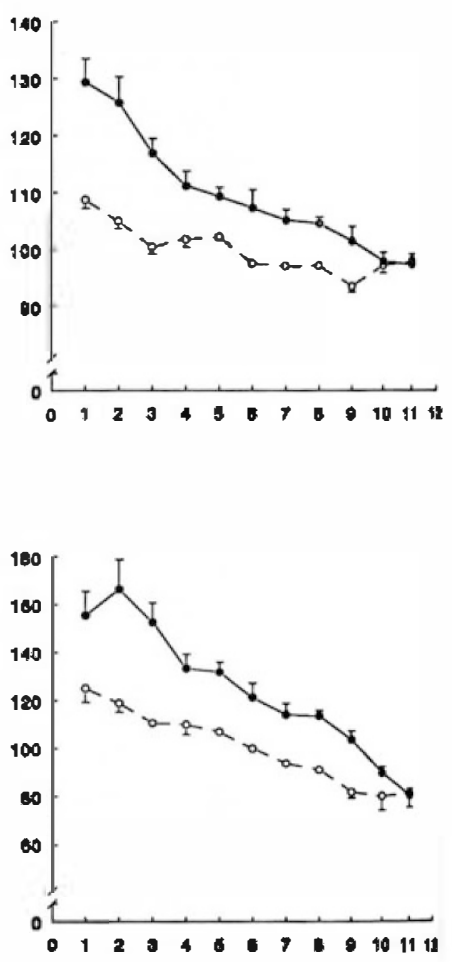

Figure 3. Dose effects of ketamine on average sample amplitude (top row) and density of delta waves/minutes of NREM sleep (bottom row). As in Figure 2, the data for each measure are plotted as percentages of the 11-hour saline mean. Both measures of delta intensity appear to show significant dose effects with ANOVA (Table 2). However, because of limitations in statistical design (see Methods) this apparent dose dependence requires confirmation.

consequence, the average ( 11 hours) increase in IA/minute above control values after ketamine $(34 \%$; from 899 \pm 217 to $1200 \pm 256 \mathrm{uV} \times \mathrm{sec} / \mathrm{min}$ ) was nearly three times as large as that produced by deprivation ( $12 \%$; from $1252 \pm 415$ to $1399 \pm 467 \mathrm{uV} \times \mathrm{sec} / \mathrm{min})$. Therefore, although it is possible that sleep loss following the ketamine injections made some small contribution to the delta increase, it could not have been responsible for the bulk of the effect.

\section{DISCUSSION}

The number of substances claimed to play a role in NREM sleep regulation is quite large and this literature has been thoroughly reviewed by Borbely and Tobler (1989) and Inoue (1989). Neither of these extensive reviews describes a pharmacologically induced increase in delta intensity of the magnitude found here with ketamine.

Although ketamine affects multiple receptor systems, one of its most important actions is a noncompetitive blockade of the cation channel gated by the NMDA receptor system. It is this blockade that is thought to underly its metabolic effects, which it shares with the more specific channel blocker MK-801. It is therefore of interest that other lines of evidence sug. gest that excitatory amino acid (EAA) systems may be involved in sleep regulation. Direct brain administration of EAA agonists and antagonists alters sleep-related electrophysiology (Armstrong-James and Fox 1988; Stutzmann et al. 1988; Juhasz et al. 1990; Milasius et al. 1990). Glutamate-like immunoreactivity has been found in many hypothalamic nuclei (van den Pol 1991) and recent evidence (Cahill and Menaker 1989; Ohiet al. 1991) suggests that EAAs serve as presynaptic trans. mitters for the retinal input to the suprachiasmatic nuclei. It has long been suspected that the hypothalamus plays a role in sleep regulation, as it does in or. ganismic homeostasis generally. More directly, the suprachiasmatic nuclei are known to control the circadian activity cycle of rodents. The finding here that ketz mine blockade of the NMDA-gated cation channel stimulates NREM sleep and delta intensity adds to the evidence that implicates EAA systems in sleep regulation.

The results of our experiment are consistent with, but can provide only limited support for, the "inten. sity" hypothesis of the homeostatic model of delta sleep. Although this hypothesis predicted the results weob. tained, it is quite possible that the causal factors were 
Table 2. Repeated-Measures $\mathrm{ANOVA}^{1}$ for Dose Response of Ketamine Effects on Delta EEG within NREM

\begin{tabular}{lcccc}
\hline Variable & $\begin{array}{c}\boldsymbol{F} \\
\text { (dose } \mathbf{~ i n ~} \mathbf{~ m g} / \mathbf{k g})\end{array}$ & $\mathbf{5 0}$ vs $\mathbf{1 5}^{\mathbf{2}}$ & $\mathbf{5 0}$ vs $\mathbf{2 5}$ & $\mathbf{2 5} \mathbf{~ v s ~} \mathbf{1 5}^{\mathbf{2}}$ \\
\hline Avg sample amp & $5.15^{\star}$ & SIG & NS & NS \\
Time in delta/min & $10.83^{\star \star}$ & SIG & SIG & NS \\
Total time in delta & $11.85^{\star *}$ & SIG & SIG & NS \\
IA/min & 3.90 & & & SIG \\
Total IA & $8.17^{\star *}$ & SIG & NS \\
Mean delta freq. & 3.21 & & & \\
\hline
\end{tabular}

${ }^{*} p<0.05$.

$\star * p<0.01$.

${ }^{1}$ BMDP 2V (Dixon et al. 1990) with time as a repeated measure, dose as a grouping factor, and saline value as a covariate.

${ }^{2}$ Bonferroni multiple comparison test for significance at $\alpha=0.05$.

SIG, significant; NS, not significant.

$A$

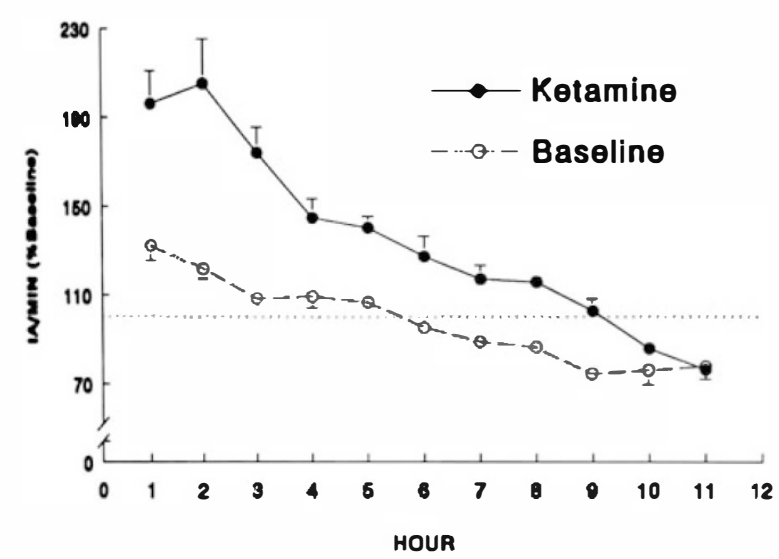

1

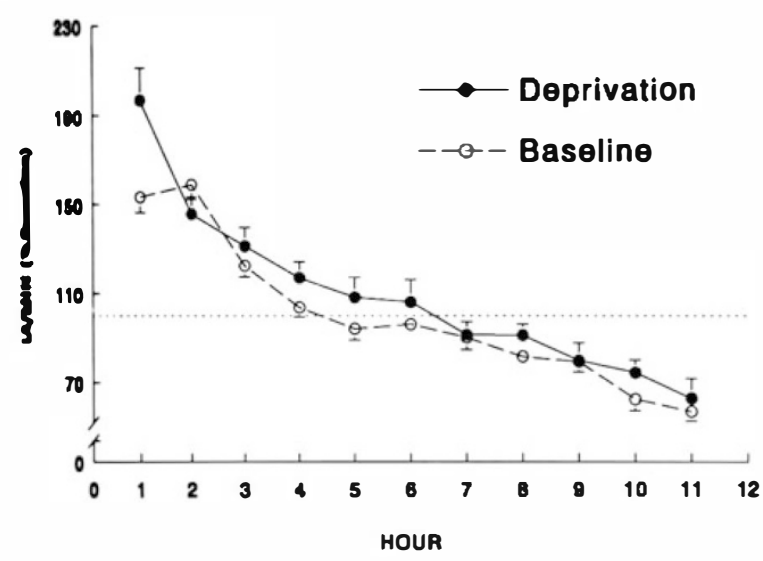

forese 4. A comparison of the effects on delta IA/minute in NREM sleep in the light period of $50 \mathrm{mg} / \mathrm{kg}$ of ketamine and Yhours of total sleep deprivation ( $n=5$ rats in each experieent). All values are expressed as a percentage of the 11-hour aen of the control condition (shown by dotted line at $100 \%$ ). Diprivation wascarried out with gentle handling. This figure tows that the ketamine effects on delta intensity are not atthutable to the sleep loss that followed the ketamine injecins (see text). other than augmented limbic metabolism or EAA perturbation. For example, the delta stimulation may have resulted from an hitherto unknown, long-lived effect of ketamine or its metabolites on sleep systems rather than being a consequence of altered waking limbic metabolism. Moreover, since ketamine produces a complex pattern of metabolic change throughout the brain, the delta stimulation may result from metabolic perturbations in nonlimbic structures. It is also possible that the delta effect is mediated by ketamine actions on nonNMDA receptors such as sigma opioids, which depress rather than stimulate limbic metabolism (London et al. 1988). These possibilities can be tested experimentally.

One must also recognize that an increase in delta EEG amplitude and density does not necessarily indicate that physiologic sleep processes have been stimulated. Evidence for such stimulation requires that the appropriate behavioral change also occurs. This consideration has been neglected in pharmacologic studies of sleep. In the present case, one would need to show that arousal threshold after ketamine has been increased with a time course that parallels the increase in delta intensity. Drugs that meet both behavioral and EEG criteria could point to a new class of hypnotics.

One final methodologic point is worth noting. The rationale of our study was to alter brain chemistry and metabolism during waking and then to examine the effects on subsequent sleep. This paradigm is seldom employed in current sleep research. The findings here suggest that it is a useful approach to the basic pharmacology of sleep.

\section{ACKNOWLEDGMENTS}

This work was supported in part by the Department of Veterans Affairs and by NIA 5R01 AG07224. We thank Keri Butler and Noah Feinberg for expert technical assistance. We also received excellent help from the following former U.C. Davis students: Denise Bilbaeno, Ken Jiang, and Jin Kim. 


\section{REFERENCES}

Armstrong-James M, Fox K (1988): Evidence for a specific role for cortical NMDA receptors in slow-wave sleep. Brain Res 451:189-196

Bergmann BM, Mistlberger RE, Rechtschaffen A (1987): Period-amplitude analysis of rat electroencephalogram: Stage and diurnal variations and effects of suprachiasmatic nuclei lesions. Sleep 10:523-536

Borbely AA, Tobler I (1989): Endogenous sleep-promoting substances and sleep regulation. Physiol Rev 69:605-670

Cahill GM, Menaker M (1989): Effects of excitatory amino acid receptor antagonists and agonists on suprachiasmatic nucleus responses to retinohypothalamic tract volleys. Brain Res 479:76-82

Campbell IG, Feinberg I (1993): Dissociation of delta EEG amplitude and incidence in rat NREM sleep. Brain Res Bull 30:143-147

Chugani HT, Phelps ME, Mazziotta JC (1987): Positron emission tomography study of human brain functional development. Ann Neurol 22:487-497

Crosby G, Crane AM, Sokoloff L (1982): Local changes in cerebral glucose utilization during ketamine anesthesia. Anesthesiology 56:437-443

Dixon, WJ, Brown MB, Engelman L, Jennrich RI (1990): BMDP Statistical Software Manual. Berkeley, University of California Press

Feinberg I (1974): Changes in sleep cycle patterns with age. J Psychiatry Res 10:283-306

Feinberg I (1989): Effects of maturation and aging on slowwave sleep in man: Implications for neurobiology. In Wauquier A, Dugovic C, Radulovacki M (eds), Slow Wave Sleep: Physiological, Pathophysiological, and Functional Aspects. New York, Raven Press, pp 31-48

Feinberg I, March JD, Fein G, Floyd TC, Walker JM, Price L (1978): Period and amplitude analysis of $0.5-3 \mathrm{c} / \mathrm{sec}$ activity in NREM sleep of young adults. Electroencephalogr Clin Neurophysiol 44:202-213

Feinberg I, Fein G, Floyd TC (1980): Period and amplitude analysis of NREM EEG in sleep: Repeatability of results in young adults. Electroencephalogr Clin Neurophysiol 48:212-221

Feinberg I, March JD, Floyd TC, Fein G, Aminoff MJ (1984): Log amplitude is a linear function of log frequency in NREM sleep EEG of young and elderly normal subjects. Electroencephalogr Clin Neurophysiol 58:158-160

Feinberg I, March JD, Flach K, Maloney T, Chern W-J, Travis $\mathrm{F}$ (1990a): Maturational changes in amplitude, incidence and cyclic pattern of the 0 to $3 \mathrm{~Hz}$ (Delta) electroencephalogram of human asleep. Brain Dysfunc 3:183-192

Feinberg I, Thode HC, Chugani HT, March JD (1990b): Gamma distribution model describes maturational curves for delta wave amplitude, cortical metabolic rate and synaptic density. J Theor Biol 142:149-161

Franken P, Dijk DJ, Tobler I, Borbely AA (1991): Sleep deprivation in rats: Effects on EEG power spectra, vigilance states, and cortical temperature. Am J Physiol 261: R198-R208

French J, Domino EF (1988): Comparative effects of phency- clidine, ketamine and MK-801 on the rat electroencephalogram. In Domino EF, Kamenka J-M (eds), Sigma and Phencyclidine-like Compounds as Molecular Probes in Biology. Ann Arbor, MI, NPP Books, pp 463-472

Hammer RP, Herkenham M (1983): Altered metabolic activity in the cerebral cortex of rats exposed to ketamine. J Comp Neurol 220:396-404

Inoue S (1989): Biology of Sleep Substances. Boca Raton, FL, CRC Press

Juhasz G, Kekesi K, Emri Z, Soltesz I, CrunelliV (1990): Sleeppromoting action of excitatory amino acid antagonists: A different role for thalamic NMDA and non-NMDA receptors. Neurosci Lett 114:333-338

Kennedy C, Sokoloff L (1957): An adaptation of the nitrous oxide method to the study of the cerebral circulation in children: Normal values for cerebral blood flow and cerebral metabolic rate during childhood. J Clin Invest 36:1130-1137

Ktonas PY, Gosalia AP (1981): Spectral analysis vs periodamplitude analysis of narrow band EEG activity: A comparison based on the sleep delta-frequency band. Sleep 4:193-206

Kurumaji A, Nehls DG, Park CK, McCulloch J (1989): Effects of NMDA antagonists, MK-801 and CPP, upon local cerebral glucose use. Brain Res 496:268-284

London ED, Dam M, Weissman AD (1988): Different patterns of cerebralglucose utilization produced by phencyclidine and $d$-N-allylnormetazocine. In Domino EF, Kamenka $\mathrm{J}-\mathrm{M}$ (eds), Sigma and Phencyclidine-like Compounds as Molecular Probes in Biology. Ann Arbor, MI, NPPBooks, pp 297-307

Meibach RC, Glick SD, Cox R, Maayani S (1979): Localization of phencyclidine-induced changes in brain energy metabolism. Nature 282:625-626

Milasius AM, Grinevicius KK, Lapin IP (1990): Effect of quinolinic acid on wakefulness and sleep in the rabbit. Neural Transmiss 82:67-73

Ohi K, Takashima M, Nishikawa T, Takahashi K (1991): $\mathrm{N}$-methyl-D-aspartate receptor participates in neuronal transmission of photic information through the retino hypothalamic tract. Neuroendocrinology 53:344-348

Stutzmann JM, Lucas M, Blanchard JC, Laduron PM (1988): Riluzole, a glutamate antagonist, enhances slow wave and REM sleep in rats. Neurosci Lett 88:195-200

Tobler I, Borbely AA (1986): Sleep EEG in the rat as a func. tion of prior waking. Electroencephalogr Clin Nevrophysiol 64:74-76

Trachsel L, Tobler I, Borbely AA (1988): Electroencephalogram analysis of non-rapid eye movement sleep in rats. Am J Physiol 255:R27-R37

Uchida S, Maloney T, Feinberg I (1992): Beta (20-28 Hz) and delta $(0.3-3 \mathrm{~Hz})$ EEG oscillate reciprocally across NREM and REM sleep. Sleep 15:352-358

van den Pol AN (1991): Glutamate and aspartate immunorex. tivity in hypothảlamic presynaptic axons. J Neuroso 11:2087-2102

Weissman AD, Dam M, London ED (1987): Alterations inlocal cerebral glucose utilization induced by phencyclidine. Brain Res 435:29-40 